\title{
Relationship Between Latent Heat Flux and Sea Surface Temperature in Alexandria Eastern Harbor, Egypt
}

\author{
Maged M.A. Hussein ${ }^{1, *}$ (1) \\ ${ }^{1}$ National Institute of Oceanography and Fisheries, Physical Oceanography Lab, Alexandria, Egypt.
}

\begin{abstract}
How to cite
Hussein, M.M.A. (2022). Relationship Between Latent Heat Flux and Sea Surface Temperature in Alexandria Eastern Harbor, Egypt. Turkish Journal of Fisheries and Aquatic Sciences, 22(6), TRJFAS20642. http://doi.org/10.4194/TRJFAS20642
\end{abstract}

\section{Article History}

Received 17 September 2021

Accepted 13 Janurary 2022

First Online 18 Janurary 2022

\section{Corresponding Author}

Tel.: +01002067829

E-mail: maged_hussain1@yahoo.com

\section{Keywords}

Cross correlation

Humidity difference

Wind speed

SST

\begin{abstract}
The immersed sensor data in Alexandria Eastern Harbor (AEH) are analyzed to explore the relation between latent heat flux (LHF) from the AEH and the sea surface temperature (SST). Output results represent that the LHF continued to rise with SST $\geq 292 \mathrm{~K}$, while LHF increases with decreasing SST at SSTs lower than $292 \mathrm{~K}$, However, the relationship cannot be expounded by thermodynamic investigation alone. Consequently, the analysis of humidity differences $(\Delta q)$ and wind speeds represent that the $\Delta \mathrm{q}$ primarily determines the sharp increase in LHF while at high SST, and a decrease in wind speed is mostly responsible for the low LHF at low SST. The temporal analysis of the two time periods, namely $\leq 90$ days (seasonal time scale) and $\leq 30$ days (monthly timescale), reveals that high LHF above warm SST was operative on the two time periods. The cross-correlation between SST and LHF on these time periods was characterized by a one-day lag with correlation coefficients of 0.47 and 0.25 , respectively.
\end{abstract}

\section{Introduction}

The flux of latent heat in the warm water of oceans is a much crucial process in the interaction between the ocean and the atmosphere system. The flux of latent heat contributes as a second component after shortwave radiation of the sea surface energy budget (Zhang and McPhaden, 1995).

Knowledge improvement of the heat fluxes between the atmosphere and ocean is important and fundamental for understanding the climate system. The fluxes of ocean surface also perform an important function in decisive processes, such as the formation of deep water. The overall heat budget comprises two main components of radiation and turbulence. The radiation components are the shortwave and longwave radiation respectively absorbed and emitted by the ocean. The second is the turbulent components, which comprise the fluxes of latent (energy loss by evaporation) and sensible (energy loss or gain by convection) heat (Ruiz et al., 2008).

The motion of the ocean and atmosphere is responsible for redistributing the sun energy arriving at Earth. The air - sea interaction (surface heat and momentum fluxes) plays an essential role or function in weather and climate determination through the distribution process (Murakami and Kawamura, 2001).

The relationship between LHF and SST has been studied, but most studies are limited to the tropical Pacific (Zhang and McPhaden 1995). Zhang and 
McPhaden (1995) studied the LHF and SST relationship using data from the moored buoy at the equatorial Pacific and found a threshold SST of $301 \mathrm{~K}$. The LHF and SST relationship is contrasting below and above such a threshold. LHF increases/decreases with SST at low/high SST, revealing a relationship that cannot be demonstrated only by thermodynamic considerations. Analysis of the surface humidity gradients $(\Delta q)$ and wind speeds indicated that the vertical humidity difference primarily defines the LHF at low SST and a sharp decrease in wind speed is mostly accountable for the low LHF at high SST. Zhang and McPhaden (1995) showed that the atmospheric process leading towards low LHF over high SST mainly relies on force on the seasonal time scale (period longer than 90 days). Increases in speed of wind can raise the sensible and latent heat loss from the ocean, decreasing the SST and the $\Delta \mathrm{q}$. Consequently, the relationship between wind speed and LHF versus $\Delta q$ can vary for the same unit SST change in different basins (Fairall et al., 1996, 2003). Nisha et al. (2012) suggested that the contrasting thermodynamic and dynamic processes of LHF at various ranges of SST help maintain the north Indian Ocean equilibrium temperature. Liu and Gautier (1990) studied the relationship between SST and LHF during the 1982-1983 El Nino using satellite measurement of the surface variables. They fond that the anomalous SST change during the El Nino episode is well correlated with the anomalous LHF in the central and eastern equatorial and southern tropical Pacific. Moreover, high evaporation corresponds to the cooling of the ocean surface and vice versa.

Comprehending the function or role of SST on LHF through its thermodynamic and dynamic effects is an important precondition to determine how the climate is preserved by the Earth through the transport of energy and its expected changes (Kumar 2017). Multiple studies focused on the role of SST on flux exchanges (Frankignoul and Hasselmann 1977; Wallace 1992; Zhang and McPhaden 1995; Barsugli and Battisti 1998; Wu et al. 2006, 2007; Gao et al. 2013; Nisha et al. 2012). Ramanathan and Collins (1992) showed that at high SST (>300K) the surface air is convectively unstable. The unstable area is subject to low level convergence, limiting the LHF due to low wind speed at the convergence center (Neelin and Held 1987; Liu 1988). Small LHF is observed in the eastern equatorial Pacific and Atlantic due to low wind speed and upwellinginduced cold SSTs and in high latitudes due to poleward decrease of SSTs (Chou et al., 2003; Feng and Li, 2006). The Northern Arabian Sea and Bay of Bengal behave exceptionally in the temperature range of $25^{\circ} \mathrm{C}-28^{\circ} \mathrm{C}$. Considering the sensitivity of LHF to SST (Kumar et al. 2017), air temperature increases faster than SST and favors a decrease in surface air humidity difference as the SST rise in these basins, resulting in a decrease in LHF. The heat fluxes between air and sea are considerably components of the climate system, while the atmosphere and ocean exchange energy and retain the system of the Earth in a "balanced" climate state (Kumar et al. 2017). LHF is the heat utilized to evaporate water from the ocean, resulting in surface Ocean cooling, which is allowed to leave to warm the atmosphere during vapor condensation to form clouds (Taylor et al. 2003). LHF also plays a centric role in coupling the ocean and the atmosphere. This coupling involves thermodynamical and dynamical (e.g., fluxSST) feedbacks between the atmosphere and ocean.

Sobel (2003) and Seager et al. (2003) investigated the SST-heat flux response or feedback in the context of global energetics. Sobel (2003) proposed that the deep convective clouds above the warm water decrease the amount of solar radiation at the surface, which must be maintained by the LHF.

The Mediterranean Sea is a deep, semi enclosed and tideless sea. The Sicily Strait is relatively shallow, causing a degree of isolation between the Western and Eastern Mediterranean, while the Adriatic and Aegean seas are also semi closed expansions of the original water body. Evaporation is around three times more than precipitation in the Mediterranean Sea. The evaporated water vapor from the Mediterranean Sea can be transported above land regions, demonstrating heat energy loss during condensation. Consequently, evaporation, condensation, and overland transportations are important procedures and mechanisms for water relocation in the atmosphere (Lolis et al., 2004). The Mediterranean Sea circulation is mainly determined by the exchange of freshwater and heat between the sea and atmosphere (Sanchez-Gomez et al., 2011). Such an exchange depends on the ocean characteristics and meteorological conditions. The water and heat fluxes play a key role in the formation of dense water and in the Mediterranean Sea thermohaline circulation (Béthoux et al., 1999). Consequently, both affect the characteristics of the water mass of the Mediterranean Sea (Béthoux et al., 1999; Potter \& Lozier, 2004; Millot et al., 2006).

The current study aims to define and investigate the relation between sea surface temperature (SST) and latent heat flux (surface evaporation) of Alexandria Eastern Harbor (AEH) using hourly data obtained from the immersed sensor.

\section{Material and Methods}

The AEH is a shallow, nearly enclosed, and semicircular basin (Figure 1). This harbor occupies nearly a central part of the Alexandria coast with an area of approximately $2.80 \mathrm{~km}^{2}$. AEH is linked to the Mediterranean Sea via two outlets or openings: the main central outlet is called El-Boughaz and the second outlet is called El-Silsila. The slopes of the harbor seabed are gradually seaward with an average depth of $5 \mathrm{~m}$ into the $A E H$ and reach a maximum depth of $13 \mathrm{~m}$ at the extreme eastern corner of El-Boughaz (Hussein \& ElGeziry, 2014; Hussein, 2018; Hussein, 2019). 
The dataset used in the present work comprises the continuous hourly SST records from June 01, 2019 to May 29, 2020. This dataset illustrates the following available continuous records from the device: (LTC Level Logger), temperature, and conductivity logger immersed approximately $1.5 \mathrm{~m}$ under the water surface in AEH.

Meteorological data (air temperature, relative humidity, wind speed and dew point temperature) were available for the study period (June 01, 2019 to May 29, 2020). The meteorological hourly data time series under investigation was taken from the following website: http://www.wunderground.com

The algorithm, which is used in this study to estimate the surface heat, moisture, and momentum fluxes, is similar to the types of algorithms that are typically used for the computation of ocean surface fluxes (Zhang \& McPhaden, 1995; Zeng et al., 1998; Renfrew et al., 2002; Fairall et al., 2003; Hussein, 2019). Sensible heat $\left(F_{h}\right)$, latent heat $\left(F_{q}\right)(L H F)$, and momentum $\left(F_{m}\right)$ fluxes $\left(\mathrm{W} / \mathrm{m}^{2}\right)$ are calculated with bulk aerodynamic methods (Zhang \& McPhaden, 1995; Abbasi et al., 2017; Hussein, 2019).

$$
\begin{aligned}
& F_{h}=\rho_{a} C_{p} C_{h} U_{z}\left(T_{s}-T_{a}\right) \\
& F_{q}=\rho_{a} \lambda C_{e} U_{z}\left(q_{s}-q_{a}\right) \\
& F_{m}=p_{a} C_{d} U^{2}
\end{aligned}
$$

Where $\rho_{a}$ is the air density $\left(\mathrm{kg} / \mathrm{m}^{3}\right) ; C_{p}$ is the specific heat of the air (1005 J/kg. k); $C_{h}, C_{e}$ and $C_{d}$ are sensible heat, latent heat and momentum transfer coefficients, respectively; $U_{z}$ is the wind speed at height $z$ above the surface water $(\mathrm{m} / \mathrm{s}) ; T_{a}$ and $T_{s}$ are air and sea surface temperatures $\left({ }^{\circ} \mathrm{C}\right)$, respectively; $\mathrm{q}_{\mathrm{s}}$ is the saturation water vapor at water surface temperature $(\mathrm{kg} / \mathrm{kg}) ; \mathrm{q}_{\mathrm{a}}$ is the specific humidity $(\mathrm{kg} / \mathrm{kg}) ; \lambda$ is the latent heat of vaporization $(\mathrm{J} / \mathrm{kg})$. The rest of the equations used in this manuscript could be found in detail in the following references: Zhang \& McPhaden, 1995; Abbasi et al., 2017; Hussein, 2019.

\section{Results}

As essential information, the distribution of SST, temperature and humidity difference of air-sea and wind speed is represented in (Figure 2) as frequency distribution. The SST frequency distribution is equally skewed for high and low SSTs: approximately $37.63 \%$ of the total observation falls between $286 \mathrm{~K}$ to less than $292 \mathrm{~K}$ (low SST), while $37.08 \%$ of the total observations fall between $298 \mathrm{k}$ and less than $304 \mathrm{k}$ (high SST); only $25.27 \%$ of the remaining observations have SSTs between $292 \mathrm{k}$ and less than 298 k. Wind speed frequency distribution is skewed to low wind speed from 0 to less than $4 \mathrm{~m} / \mathrm{s}$ (54.39\%) rather than high wind speed from $4 \mathrm{~m} / \mathrm{s}$ to less than $10 \mathrm{~m} / \mathrm{s}$ (45.6\%). The distribution of temperature difference (SST-Ta) is highly skewed: approximately $60.43 \%$ of the total observations have SST>air temperature, while approximately the remaining $39.56 \%$ of the total observations have $\mathrm{SST}<$ air temperature, indicating that the atmospheric boundary layer in the Eastern Harbor is mostly unstable. The humidity difference distribution is moderately skewed approximately $27.47 \%$ of the total observations fall between 0 less than $4 \mathrm{~g} / \mathrm{kg}, 47.52 \%$ fall between larger than 4 and less than $8 \mathrm{~g} / \mathrm{kg}$ and $25 \%$ fall between 8 and less than $11 \mathrm{~g} / \mathrm{kg}$.

\section{Exchange Coefficients}

The exchange coefficients $\left(C_{h}\right.$ and $\left.C_{d}\right)$ measure the exchange capability of fluxes (heat, moisture, and momentum) between the ocean/sea and the atmosphere. These coefficients depend on the wind

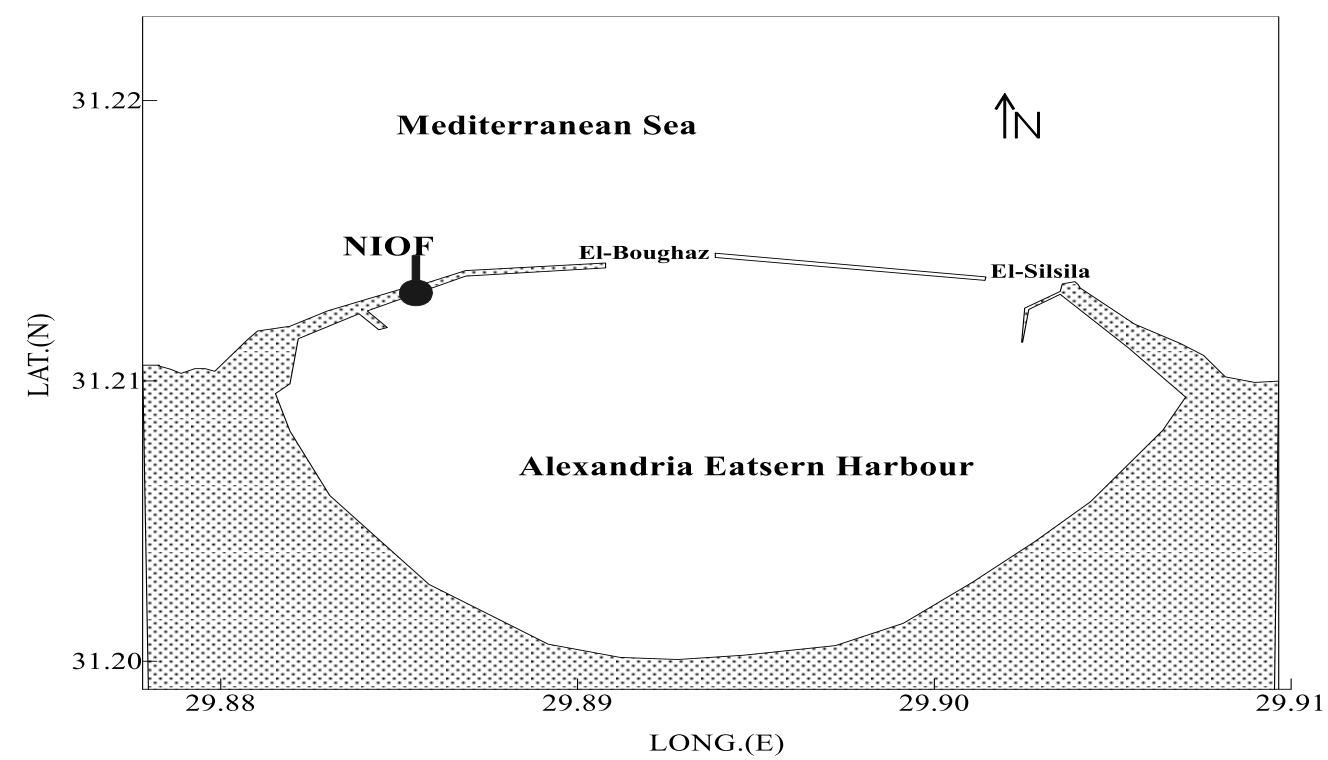

Figure 1. The location of National Institute of Oceanography and Fisheries (NIOF) at Alexandria Eastern Harbor (AEH) where the level logger (LTC) has been installed since May 2019 (El-Geziry 2013) 
speed and air stability. Figure (3) represents the scatter plot of $C_{h}$ and $C_{d}$ versus (function of) wind speed for the full data available. Drag coefficient $C_{d}$ increases from $1.07 \times 10^{-3}$ at $4 \mathrm{~m} / \mathrm{s}$ to $1.43 \times 10^{-3}$ at $9 \mathrm{~m} / \mathrm{s}$, while heat coefficient $C_{h}$ raise from $1.12 \times 10^{-3}$ to $1.32 \times 10^{-3}$. $C_{h}$ and $C_{d}$ dramatically increased considering unstable conditions and decreasing wind speed (less than $4 \mathrm{~m} / \mathrm{s}$ ). By contrast, small $C_{h}$ and $C_{d}$ are observed at a low value of wind speed during the stable boundary layer. The dependence of the exchange coefficients on wind speed is observed in Figure 3, which is consistent with that in the former study (Hussein, 2019). $C_{d}$ and $C_{h}$ (at low wind speed) scattered, indicating that the considerable dependence of $C_{h}$ and $C_{d}$ on stability conditions of the surface layer.
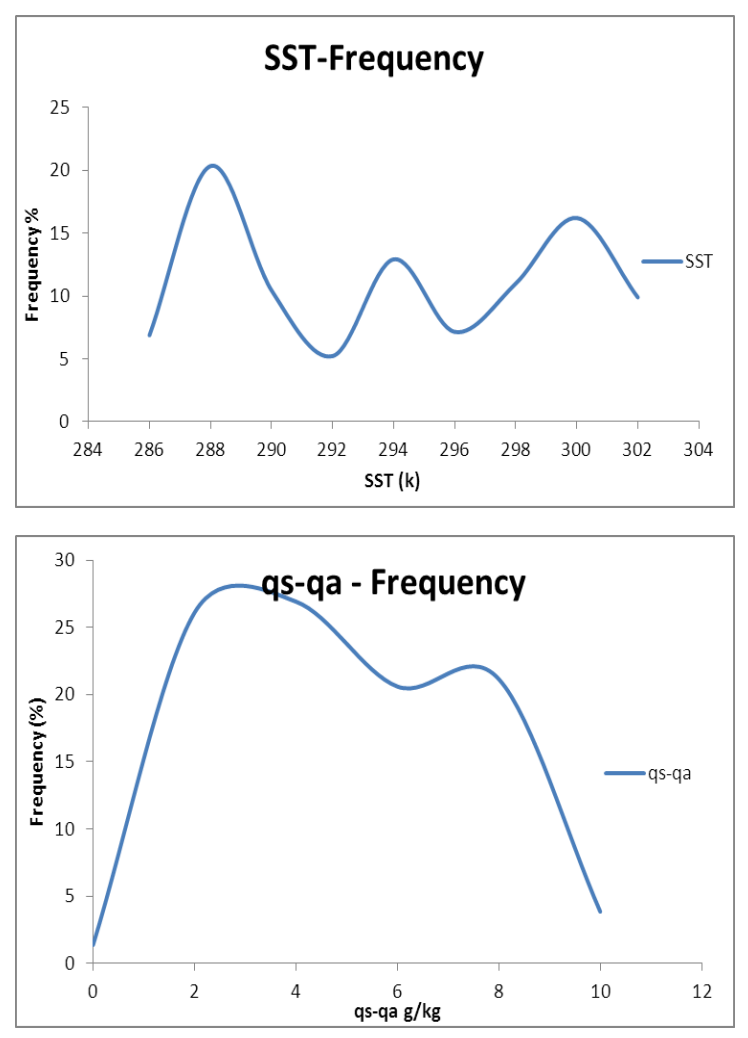

\section{SST and LHF}

SST generally has a direct relationship with evaporation from the water surface. $q_{s}$ exponentially increases with SST (Zhang \& McPhaden, 1995). If no substantial change in surface air relative humidity is observed, then evaporation from surface water will rise with increasing SST. Figure (4) left panel represents the relationship between SST and LHF. The scatterplot generally represents that LHF increases as SST rises as shown in Figure (4), demonstrating a high standard deviation of 47.3732 and an almost low $R^{2}$ value of 0.4528 .

The right panel of Figure 4 represents the average value of the $\mathrm{fLHF}$, and its standard deviation has been
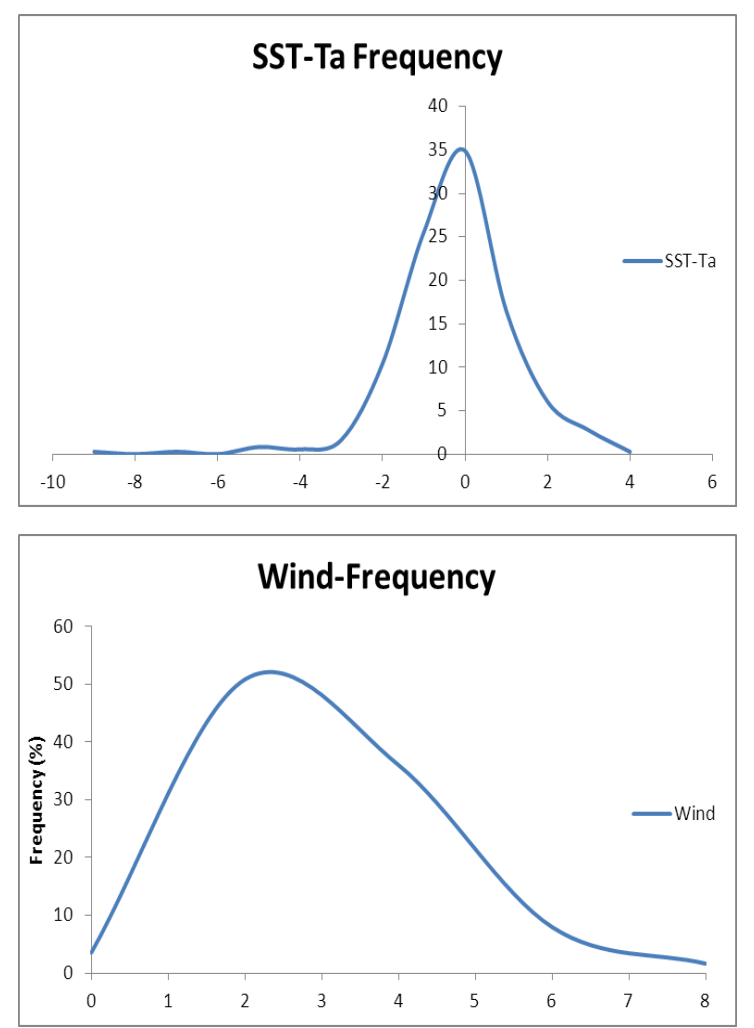

Figure 2. Frequency distribution of SST (upper left), temperature difference (upper right), humidity difference (lower left) and wind speed (lower right)
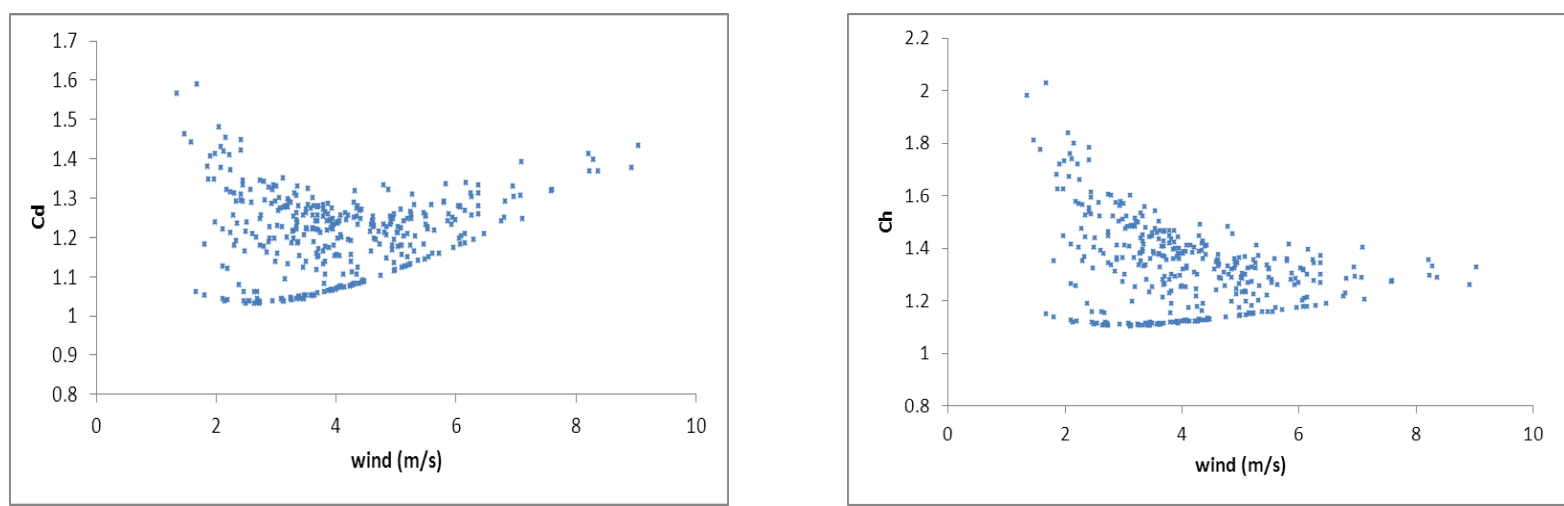

Figure 3. Scatterplots of $C_{d}$ (left), and $C_{h}$ (right) $\times 10^{-3}$ function of wind speed 
estimated for each one sea surface temperature range. The average value of latent heat flux is indicated by the blue curve and the red and green curves respectively represent the one standard deviation above and below the average value. The LHF below $292 \mathrm{~K}$ (i.e., SST $=286 \mathrm{k}$ to SST $<292 \mathrm{k}$ ) decreases with increasing SST. The slope of the latent heat flux data that coincides with SST below $292 \mathrm{k}$ is $-0.61 \mathrm{~W} / \mathrm{m}^{2} \mathrm{k}$. The LHF above $292 \mathrm{k}$ (i.e., between SST=292 $\mathrm{K}$ and $\mathrm{SST} \leq 298 \mathrm{~K}$ ) moderately increases with SST at the rate of $2.89 \mathrm{~W} / \mathrm{m}^{2} \mathrm{k}$. The LHF for SST $\geq 298 \mathrm{k}$ substantially increases at the rate of 12.76 $\mathrm{W} / \mathrm{m}^{2} \mathrm{k}$ as shown in Table (1). High variability in standard deviations is observed at the three mentioned SST intervals under these SSTs.

The LHF in Eq. (2) is characterized by the following: (1) the coefficient of thermal exchange, (2) the wind speed, and (3) the humidity difference $\left(\Delta q=q_{s}-q_{a}\right)$. Zhang \& McPhaden (1995) differentiated Eq. (2) considering sea surface temperature (SST) to determine the importance of the aforementioned parameters.

$\frac{\delta F_{q}}{\delta T_{S}}=L_{v} U \Delta q \frac{\delta C_{h}}{\delta T_{S}}+L_{v} \rho C_{h} \Delta q \frac{\delta U}{\delta T_{S}}+L_{v} \rho C_{h} U \frac{\delta \Delta q}{\delta T_{S}}$
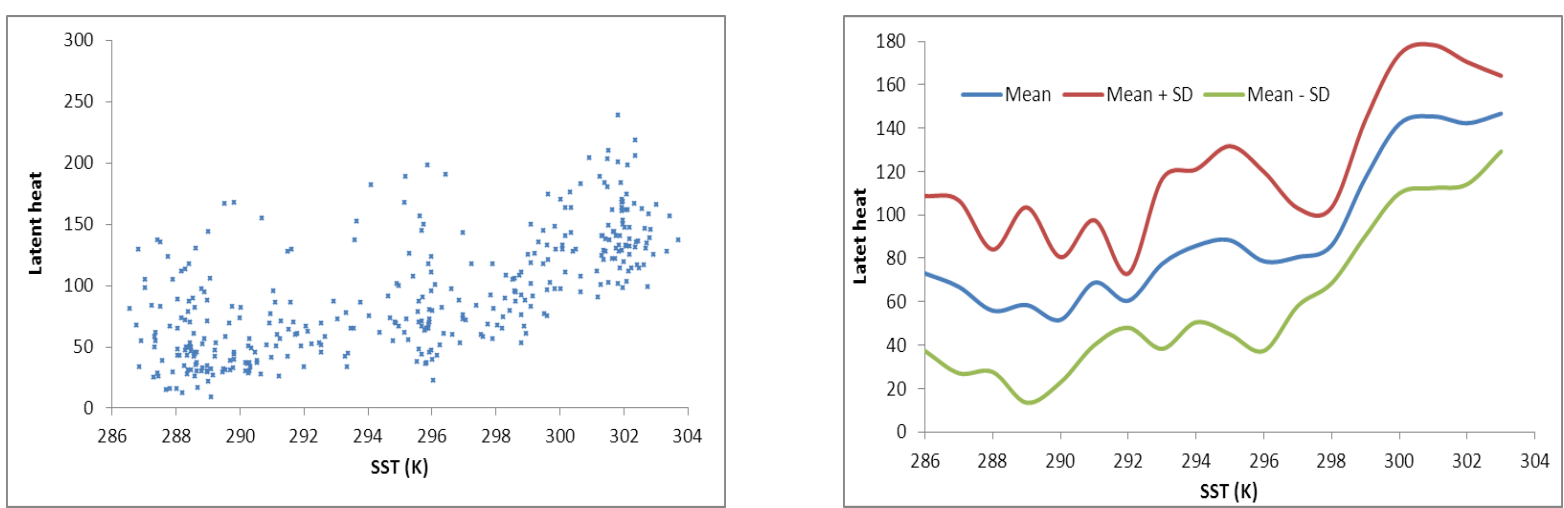

Figure 4. The relationship between SST and latent heat (left panel). Mean value of latent heat flux for each one SST interval (right panel) and mean latent heat \pm one standard deviation in each one SST.
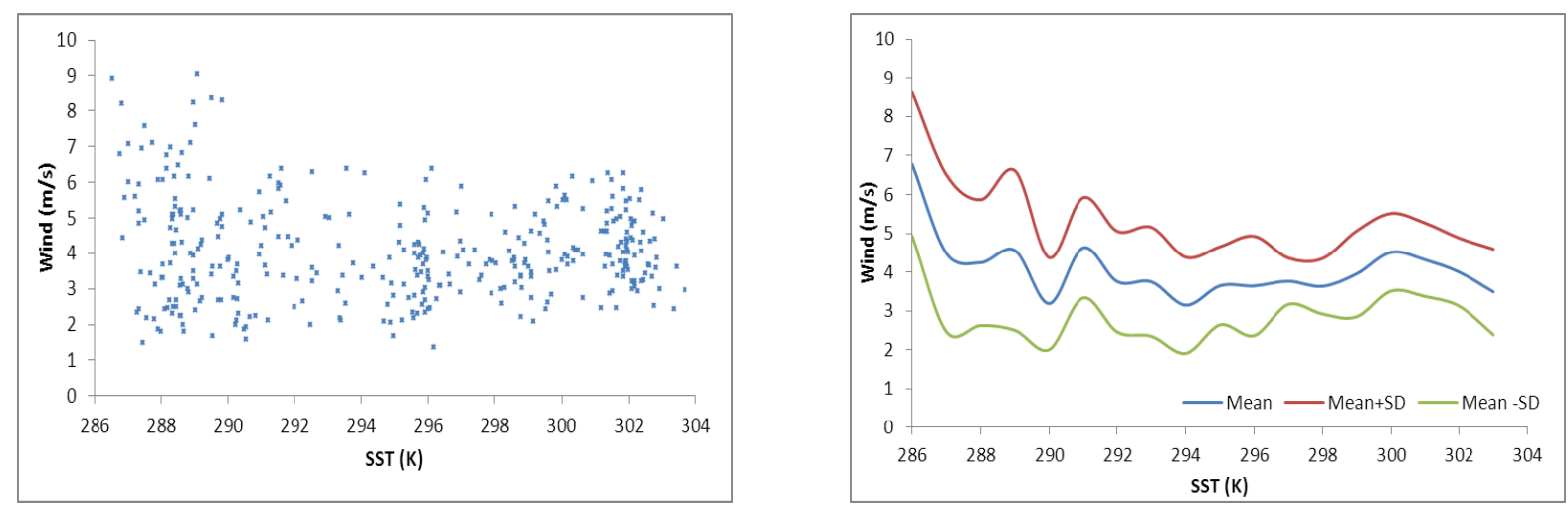

Figure 5. Relationship between SST and wind speed (left panel). Mean value of wind speed for each one SST interval (right panel) and mean wind speed \pm one standard deviation in each one SST.
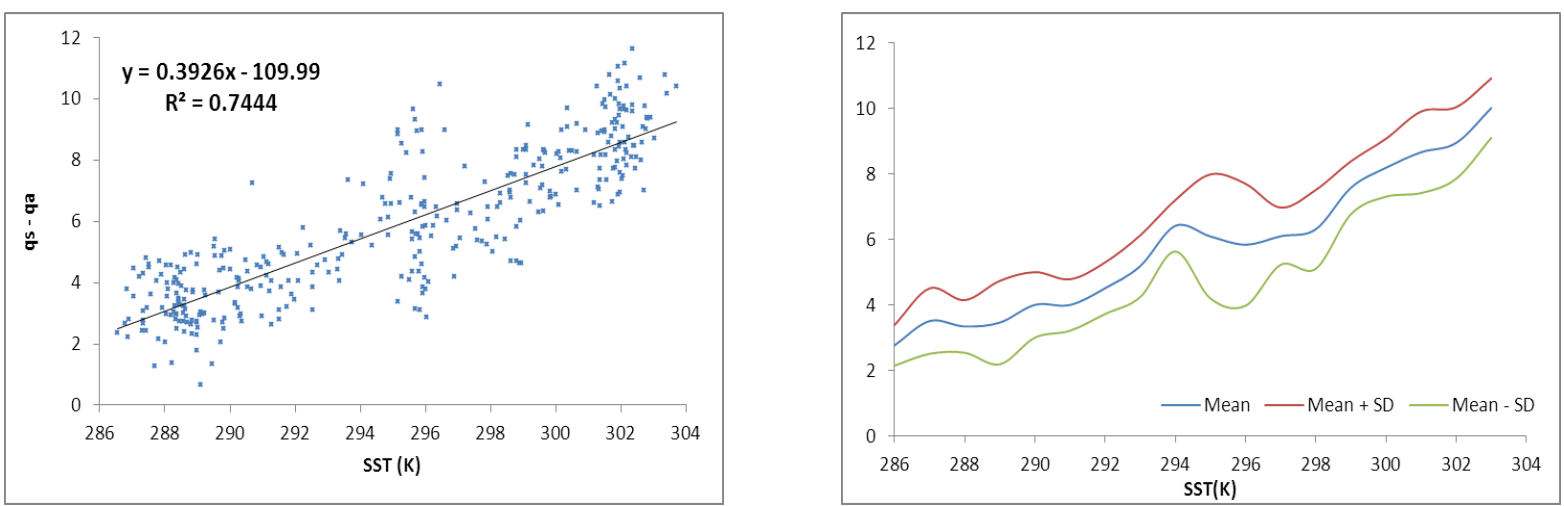

Figure 6. Relationship between SST and $\Delta \mathrm{q}$ (left panel). Mean value of $\Delta \mathrm{q}$ for each one SST interval (right panel) and mean $\Delta \mathrm{q} \pm$ one standard deviation in each one SST. 
In the above differential equation (Eq. 4), $\mathrm{Ch}_{\mathrm{h}}$ can be handled as a constant with sea surface temperature (SST). (Figure 5) right panel shows the dependence of wind speed on SST. The scatterplot illustrates that wind speed at SST $<292 \mathrm{~K}$ decreases with slope $-0.2 \mathrm{~m} / \mathrm{s} \mathrm{k}$, while that at moderate SST $292 \mathrm{~K} \leq \mathrm{SST}<298 \mathrm{~K}$ is almost constant or independent on SST with slope $0.01 \mathrm{~m} / \mathrm{s}$ k. Wind speed at high SST (i.e., $>298 \mathrm{~K}$ ) slightly increases with slope $0.06 \mathrm{~m} / \mathrm{s} \mathrm{k}$.

Figure 6 and Table 1 show the relationship between SST and $\Delta q$. The $\Delta q$ increases with SST. The slope is $0.19 \mathrm{~g} / \mathrm{kg} \mathrm{k}$ for low SST between $286 \mathrm{~K}$ and less than $292 \mathrm{~K}$, the slope is $0.26 \mathrm{~g} / \mathrm{kg} \mathrm{k}$ for moderate SST between $292 \mathrm{k}$ and less than $298 \mathrm{k}$ and that for high
SST>298 $\mathrm{K}$ the slope is $0.68 \mathrm{~g} / \mathrm{kg} \mathrm{k}$. Therefore, the increase rate of $\Delta q$ is weak and high at low and high SSTs respectively.

$\partial U / \partial T s$ and $\partial \Delta q / \partial T s$ terms are positive at high SST, causing latent heat flux to increase with SST. $\partial \Delta q / \partial T s$ term is dominated in increasing LHF with SST in Eq. 2. This term contributes $8.711 \mathrm{~W} / \mathrm{m}^{2} \mathrm{~K}$ to the total latent heat change of $12.767 \mathrm{~W} / \mathrm{m}^{2} \mathrm{~K}$ as shown in Table 1 and Figure 4. Moderate SST is similar to high SST with a low contribution of $0.677 \mathrm{~W} / \mathrm{m}^{2} \mathrm{~K}$ of $\partial \Delta \mathrm{q} / \partial \mathrm{T}$ s term to the total latent heat change $2.896 \mathrm{~W} / \mathrm{m}^{2} \mathrm{~K}$ as shown in Table 1. At low SST, terms $\partial U / \partial T s$ and $\partial \Delta q / \partial T s$ nearly have similar values and have opposite signs. The dominant effects in Eq. 2 at low SST due to the contribution of

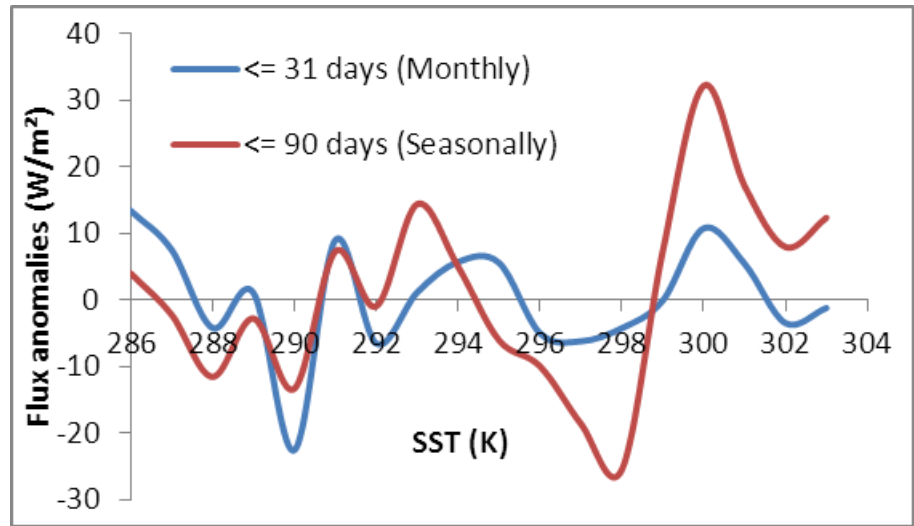

Figure 7. Anomalies of LHF as function of sea surface temperature (SST) on time periods $\leq 31$ days (monthly anomalies) and $\leq 90$ days (seasonally anomalies).
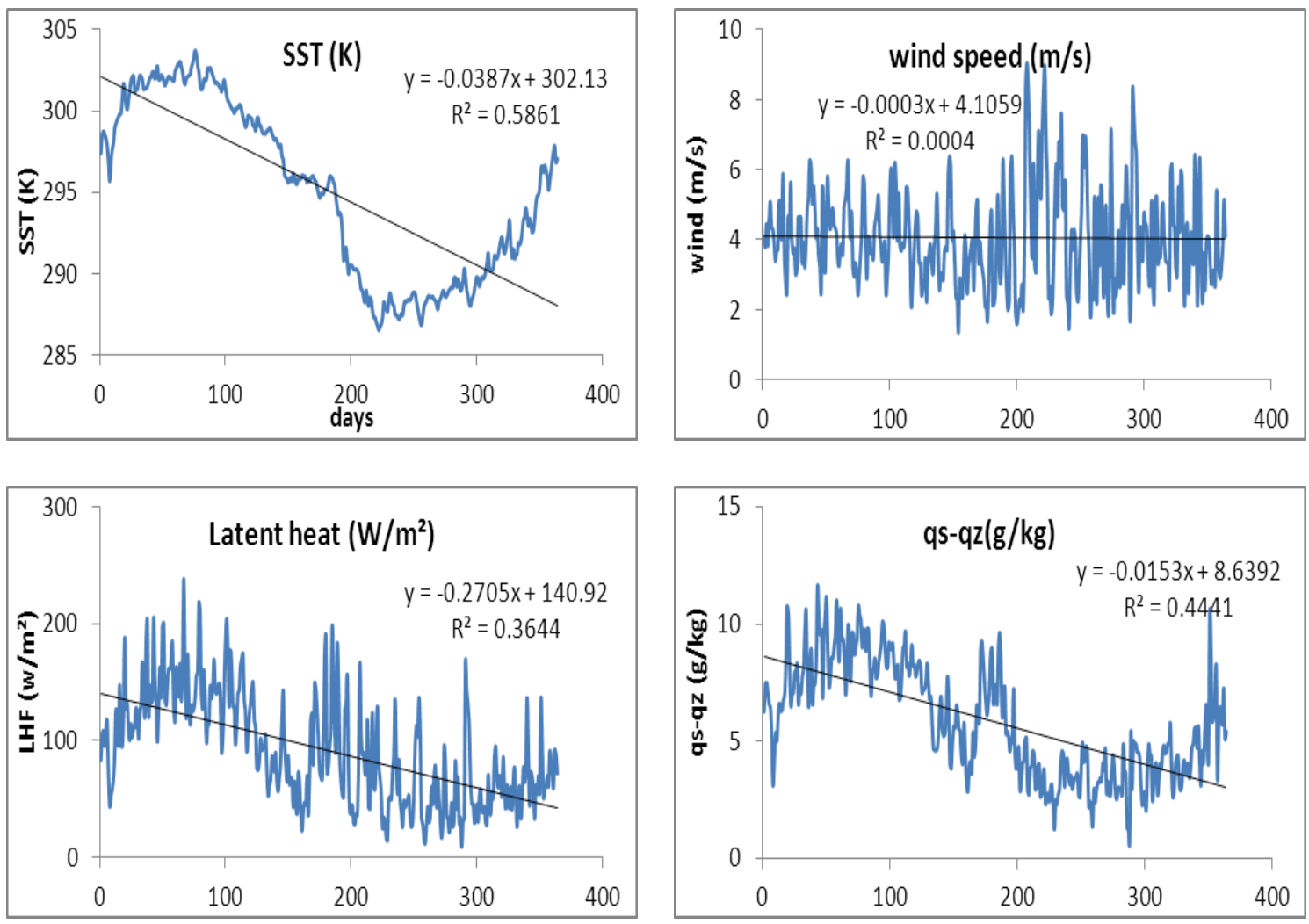

Figure 8. Time series of SST (upper left), LHF (lower right), $U$ (upper right), and $\Delta \mathrm{q}$ (lower right) 
$\partial U / \partial T s$ term yielded $-0.121 \mathrm{~W} / \mathrm{m}^{2} \mathrm{~K}$ as shown in Table 1 and Figure 5 . By contrast, the contribution of $\partial \Delta q / \partial T s$ term is $-0.119 \mathrm{~W} / \mathrm{m}^{2} \mathrm{~K}$ in Eq. 2.

The output results represented in Figures (4) to (6) indicate that the surface evaporation variations are specified initially or originally by thermodynamic (as demonstrated by $\Delta \mathrm{q}$ changes) at high SST, while surface evaporation changes are specified by wind speed variations (atmospheric dynamic) at low SST. It is comparatively not difficult to understand the function or role of thermodynamic in LHF because of the relation between SST and the saturation of water vapor. Otherwise, why the dynamics of the atmosphere combined with SST, take action to regulate the LHF is not obvious this needs some clarification.
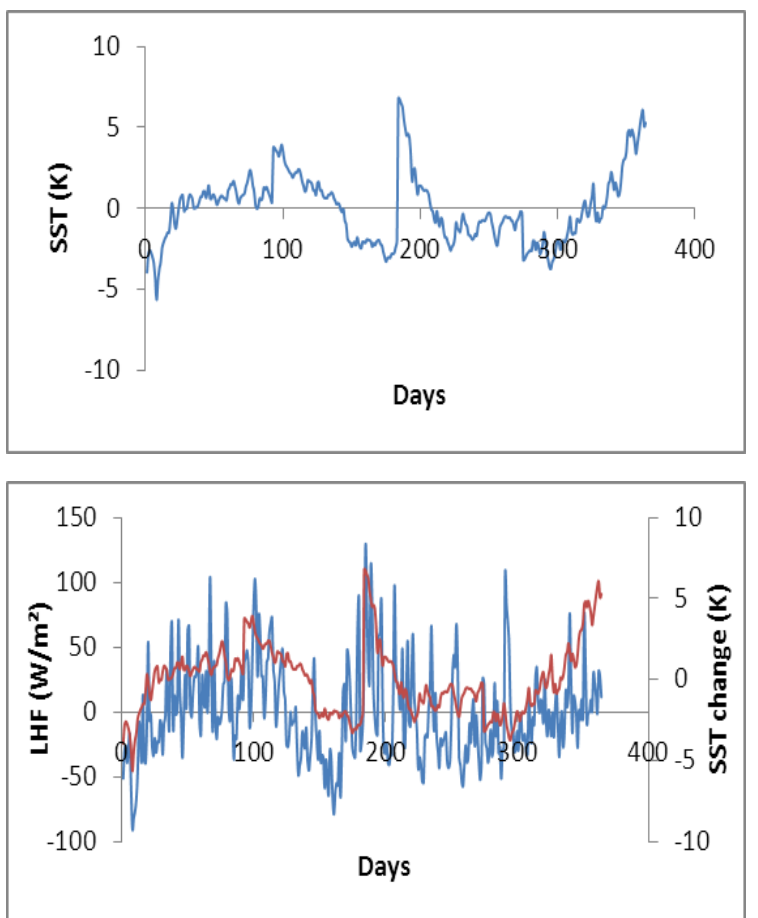

No discrepancy is observed between the output results or observations in this study, and the self-evident argument that the flux of latent heat should increase with increasing SST. However, a discrepancy is found between this intuitive argument and the output results at low SST, latent heat flux decreases with increasing SST (i.e., $286 \mathrm{~K} \leq \mathrm{SST}<292 \mathrm{~K}$ ).

\section{Temporal Variability}

This section represents the temporal variability of the relations between sea surface temperature, humidity difference, surface wind and LHF. The clarified time series of the LHF are outlined against SST to demonstrate the dependence of the LHF on sea surface
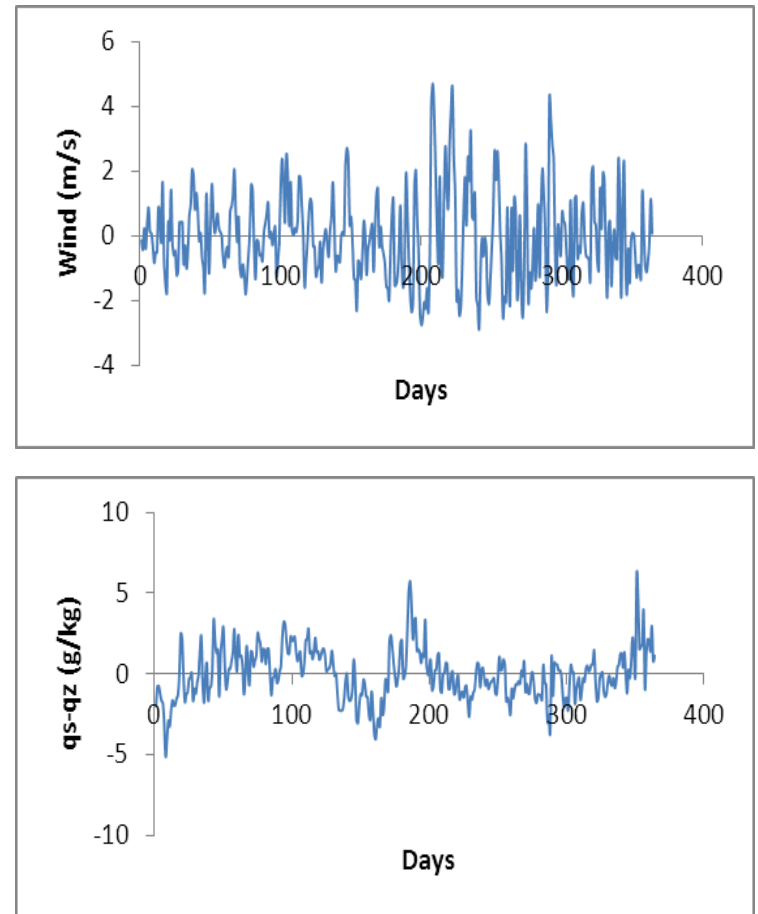

Figure 9. Time series of seasonal time period of SST (upper left), wind speed (upper right), LHF (blue line) and SST change (red line) (lower left), and humidity difference (lower right)

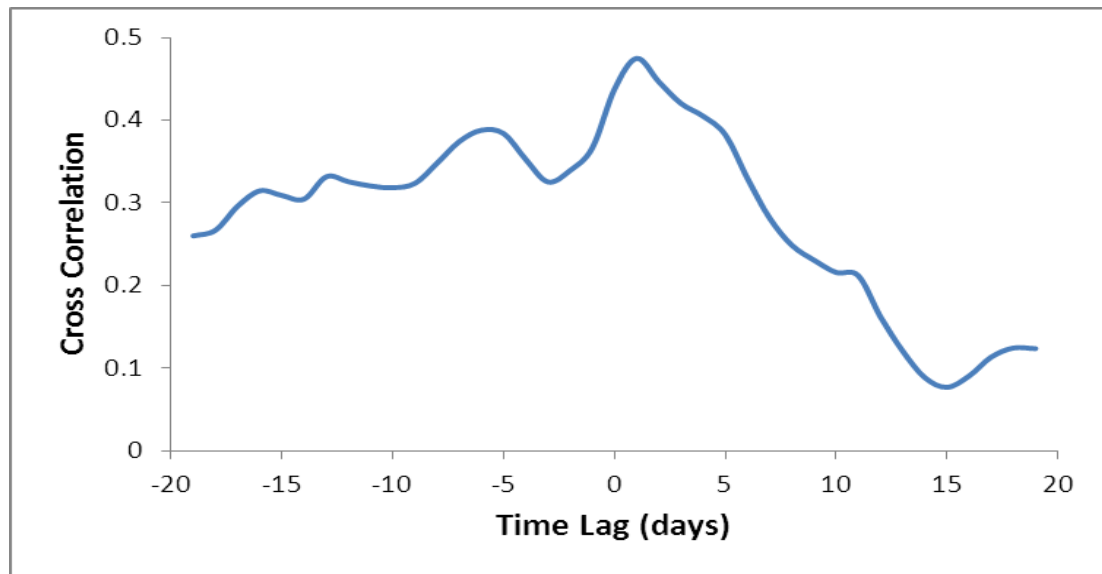

Figure 10. Cross-correlation between SST and LHF on: $\leq 90$ days 
temperature (SST) on various timescales. Figure 7 represents the LHF as a function of sea surface temperature on time periods $\leq 31$ days (monthly anomalies) and $\leq 90$ days (seasonal anomalies). The LHF has almost the same trend with different magnitude changes in anomalies in both time periods. On the time period $\leq 31$ days, the LHF decreases with SST: SSTs $\leq 288$, $\mathrm{K}$, between $291 \mathrm{~K}$ and $290 \mathrm{~K}$, between $291 \mathrm{~K}$ and $292 \mathrm{~K}$, between 293 and $\leq 298 \mathrm{~K}$ and between 300 and $\leq 302 \mathrm{k}$. Meanwhile LHF increases between the following SST: $288 \mathrm{~K}$ and $289 \mathrm{~K}, 290 \mathrm{~K}$ and $291 \mathrm{~K}, 292 \mathrm{~K}$ and $\leq 295 \mathrm{~K}, 296$ $\mathrm{K}$ and $300 \mathrm{~K}$, and $302 \mathrm{k}$ and $\leq 303 \mathrm{~K}$ (considering the high variability in LHF at high sea surface temperature i.e., above $299 \mathrm{~K}$ ). A relationship is observed between LHF and SST on the time period $\leq 90$ days. The LHF between $293 \mathrm{~K}$ and $<298 \mathrm{~K}$, and between $300 \mathrm{~K}$ and $302 \mathrm{~K}$ decreases with SST. Meanwhile, the LHF above 298K to $300 \mathrm{~K}$ and between 302 and 303K increases with SST (Figure 8).

The seasonal variation of SST shows an almost in phase relationship with LHF. Seasonal variation of $\Delta q$ is also observed, representing a phase relationship with LHF. By contrast, no apparent seasonal variation is found in wind speed time series. $\partial$ (SST)/ $\partial \mathrm{t}$ is overlaid on the LHF time series in Figure (9) as the change of SST per day to represent the relationship between LHF and SST.

The variations are present in the variables in $\mathrm{AEH}$ during the seasonal period, with a range of $\pm 5 \mathrm{~K}$ for SST, $\pm 100 \mathrm{~W} / \mathrm{m}^{2}$ for LHF, $\pm 4 \mathrm{~m} / \mathrm{s}$ for $\mathrm{U}$ (wind speed), and $\pm 5(\mathrm{~g} / \mathrm{kg})$ for $\Delta \mathrm{q}$ (humidity difference). The LHF in this time period is nearly in a phase relationship with SST and
$\Delta$ q. High and low LHFs nearly respectively coincide with high and low SSTs with a few exceptions at some of SSTs. In addition to $\Delta \mathrm{q}$, the SST change and LHF relationship indicate that the SST has an important role to defining the LHF in AEH.

As a function of time-lag for $\leq 90$-day time period (Figure 10), The SST and LHF cross-correlation represents a positive cross-correlation between SST change and LHF with a maximum of 0.47 at one-day time-lag. This finding indicates that surface LHF responds to the change in SST. The change in SST influences the humidity difference between air and sea, which is crucial in LHF values.

The shape of the cross-correlation between SST and LHF for the time period $\leq 31$ (Figure 11) is similar to that for a period $\leq 90$ days. Figure 11 demonstrates that high SSTs lead to low LHFs and vice versa.

As a function of time-lag for $\leq 30$-day time period (Figure 11), the SST and LHF cross-correlation represents a positive cross-correlation between SST change and LHF, with a maximum of 0.25 at one-day time-lag. This finding also confirms that surface LHF responds to the change in SST for period $\leq 31$ days as previously proposed for a period $\leq 90$ days.

\section{Discussion}

A global analysis of LHF sensitivity to SST is performed, with focus on the tropics, Pacific Ocean, the North Indian Ocean (NIO) and South Atlantic Ocean (SAO). Several earlier researchers argue that

Table 1. Linear regression slopes relative to SST

\begin{tabular}{lccc}
\hline & SST $(\mathrm{k})$ & SST $(\mathrm{k})$ & \\
\hline & $286-<292$ & $292-<298$ & $298-<304$ \\
$\partial F q / \partial T s$ & -0.612 & 2.896 & 12.767 \\
$\partial U / \partial T s$ & -0.201 & 0.014 & 0.064 \\
$\partial \Delta q / \partial T s$ & 0.194 & 0.260 & 0.682 \\
$\mathrm{~L} \rho \mathrm{Ch} \Delta \mathrm{q} \partial U / \partial T s$ & -0.121 & 0.007 & 0.182 \\
$\mathrm{~L} \rho \mathrm{ChU} \partial \mathrm{q} / \partial T s$ & -0.119 & 0.677 & 8.711 \\
\hline
\end{tabular}

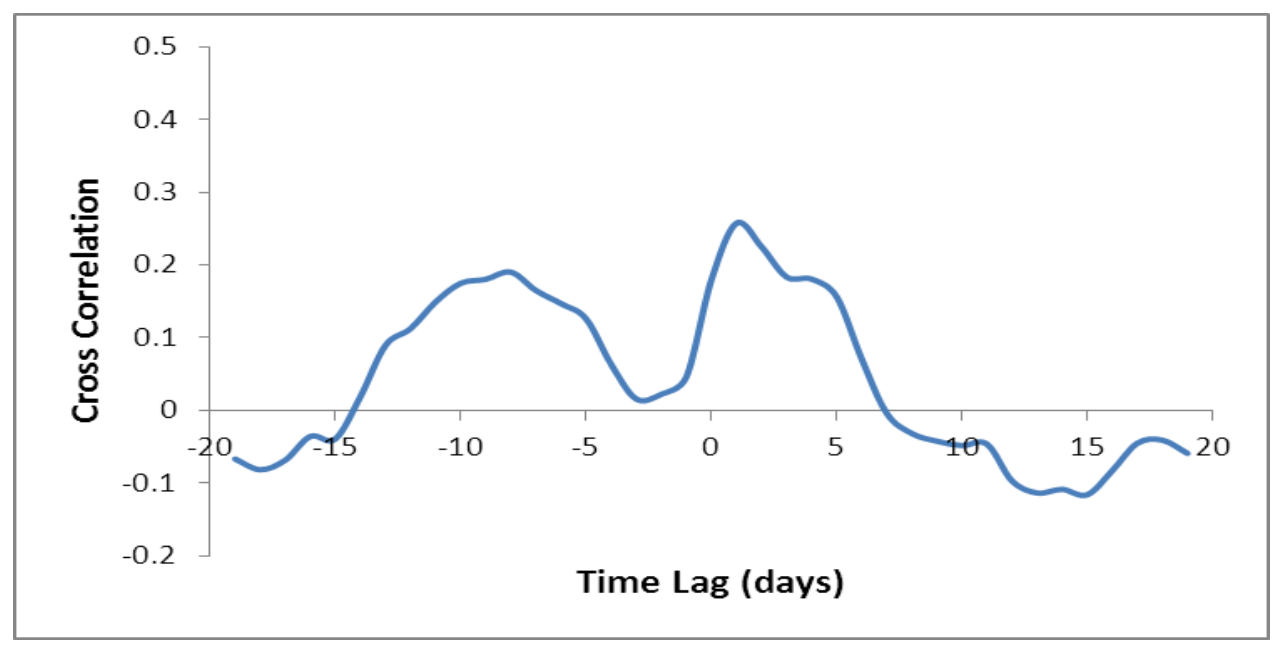

Figure 11. Cross-correlation between SST and LHF on: $\leq 31$ days 
evaporation is an important factor in regulating the tropical SST (Zhang and McPhaden, 1995). The variability of LHF and SST is related, it means that when the variations of the SST and LHF are negatively correlated, the atmosphere forces the ocean through the LHF, and that when the variations of the SST and LHF are positively correlated, the ocean forces the atmosphere (Jing et al. 2020). In the global oceans, the contributions of surface wind speed and the air-sea humidity gradient as functions of SST to the LHF variability are stronger and more pronounced in the tropical belt, especially over warm waters, with SST more than $298 \mathrm{~K}$ (Kumar et al. 2017). Gao et al. 2013 studied the global changes in LHF and found that; $70 \%$ of the total temporal variations in LHF are contributed by $\Delta q$ changes while the rest are contributed by wind variations. These results agreement with the current results, about $62.9 \%$ of the time period variations in LHF are contributed by $\Delta \mathrm{q}$ changes at moderate and high SST (SST $\geq 292 \mathrm{k}$ ) while about $37.1 \%$ are contributed by wind variations at low SST (SST<292K). Kumar et al. 2017 demonstrated the following two processes may be happening in different basins, one of them dominates over the other and leads to either decrease of LHF loss or increase it at different rates with SST: Generally, wind as a function of SST decrease the LHF in the tropical warm waters. This is because low pressure systems form over warm waters in the tropical belt that support lowlevel convergence and ascent of moist air. Surface winds are weaker over the convergence zones, and thus warm SST supports weaker winds and hence a decrease in LHF. Over warm waters, the saturation humidity of the near surface increases, thus increasing the vertical humidity gradient. Hence, increase in SST leads to an increase in the vertical humidity gradient, which then drives more LHF loss in the tropics.

These two processes are happed in the current study as the following: Stable and unstable conditions have been located above AEH at low SST (i.e., between 286 to $<292 \mathrm{~K}$ ). This finding is due to the low level convergence under unstable conditions, covering the area of study (Neelin and Held 1987). In addition to low wind speed over the study area, the convergence situation induces LHF reduction with SST ( $1^{\text {st }}$ Process).

Sui et al. (1991) found that the LHF decreases with SST when surface wind interacts with SST (the boundary layer of ocean and atmosphere are coupled) due to the reduction in wind speed. This means that the atmosphere forces the ocean through the LHF (Jing et al. 2020). This phenomenon is almost similar to the present results in the case of stable conditions at low SST as shown in Figures (4 and 5). Sui et al. (1991) confirmed that LHF characteristics can significantly vary with or without the coupling between the boundary layer of the ocean and atmosphere. LHF continued to rise with SST despite the absence of interaction between surface wind and SST due to the rise of $\Delta q$ (Sui et al., 1991, Leyba et al. 2019). This situation is almost similar to the present results represented in Figure (4) at moderate
SST (i.e., $292 \leq$ SST<298K). The wind speed is nearly constant at this SST interval as shown in Figure (5) ( $2^{\text {nd }}$ process).

LHF continued to rise with SST (positively correlated) under the aforementioned condition due to the rise of $\Delta q$ at high SST (i.e., $>298 K$ ): the wind speed slightly increases with SST at this interval of SST ( $2^{\text {nd }}$ process). In this situation the ocean forces the atmosphere (Jing et al. 2020). The current result is consistent with that obtained by the following authors: Yu et al. (2012) who showed that trends of LHF and SHF can be explained primarily by air-sea specific humidity and temperature differences while wind speed plays a minor role, also they demonstrated that the seasonal variation in the spatial pattern of the SST trend over most of the Southern Ocean is consistent with the trends in LHF and SHF. Kumar et al. (2017) suggested that in the two North Indian Ocean basins (Bay of Bengal and north Arabian Sea) there is a net increase (decrease) of LHF with respect to winds (vertical humidity gradient) with increase in SST at annual time scale. Wu and You (2018) explained that the ocean-induced positive SST anomalies increase evaporation (LHF) and surface air humidity. Cherchi et al. (2018) and Vizy et al. (2018) demonstrated that the SST trends arise as one of the largest drivers of trends in heat fluxes (LHF and SHF) in South Atlantic Ocean and over the Extend Brazil Current Region (ExtBCR). A positive trend of SST triggers an increase of the air-sea specific humidity and temperature differences, leading to larger LHF and sensible heat flux (SHF) (Leyba et al. 2019). The current result at high SST is inconsistent with that obtained by the following authors: Weare et al. (1981) found that surface LHF in the tropical western Pacific, where SST is high, is smaller than its surrounding areas. Liu et al. (1993) computed the surface LHF utilizing the satellite data, thus yielding a similar distribution pattern. Zhang and McPhaden (1995) demonstrated that the LHF in equatorial Pacific decreases with SST at high SST due to sharp decrease in wind speed, which is particularly responsible for the low LHF. Herman (2015) demonstrated that in spite of climate change related positive trends in surface wind speeds over large parts of Southern Ocean, the range of the turbulent heat flux (LHF and SHF) variability has been increasing due to decreasing air-water temperature and humidity differences. Bay of Bengal and northern Arabian Sea (North Indian Ocean basins) behaves in an exceptional way in the temperature range of $25-28^{\circ} \mathrm{C}$, for the sensitivity of LHF to SST (Kumar et al. 2017), as the temperature increases in these basins, air temperature increases faster than SST and favors a decrease in surface air humidity difference resulting in a decrease of LHF (Mathew et al 2020).

These dynamical controls on LHF lead to agreement between the present observation and the intuitive argument, that is, LHF should increase with SST at high SST. Chen et al. (2015) and Han et al. (2016) demonstrated that the influence of the atmospheric 
anomalies on SST is mainly reflected in the change of sea surface heat flux (LHF and SHF) driven by the change of local wind stress in the North Atlantic Ocean, this is another opinion could be taken into account in further future studies on AEH.

\section{Conclusion}

This study investigates the relationship between latent heat flux (LHF) and sea surface temperature (SST) in Alexandria Eastern Harbor (AEH) from June 01, 2019 to May 29, 2020. The exchange coefficients $\left(C_{h}\right.$ and $\left.C_{d}\right)$ depend on the wind speed and air stability. $C_{h}$ and $C_{d}$ dramatically increased considering unstable conditions and decreasing wind speed (less than $4 \mathrm{~m} / \mathrm{s}$ ). By contrast, small $C_{h}$ and $C_{d}$ are observed at a low value of wind speed during the stable boundary layer. The relationship between LHF and SST cannot be demonstrated by thermodynamic investigation alone. Analysis of humidity differences $(\Delta q)$ and wind speeds represent that while at high SST the $\Delta \mathrm{q}$ primarily determines the sharp increase in LHF, and at low SST a decrease in wind speed is mostly responsible for the low LHF. Through the temporal analysis of the two time periods, $\leq 90$ days (seasonal time scale) and $\leq 30$ days (monthly timescale), giving to high LHF above warm SST were operatives on the two time periods. On these time periods, the crosscorrelation between SST and LHF was characterized by a one-day lag with correlation coefficients, 0.47 and 0.25 , respectively.

The author declares that he has no known competing financial interests or personal relationships that could have appeared to influence the work reported in this research paper. This research did not receive any specific grant from funding agencies in the public, commercial, or not-for-profit sectors.

\section{Ethical Statement}

Not applicable

\section{Funding Information}

There is no funding for this manuscript

\section{Author Contribution}

The author did all the research stages of the manuscript

\section{Conflict of Interest}

The author declares that he has no known competing financial interests or personal relationships that could have appeared to influence the work reported in this research paper. This research did not receive any specific grant from funding agencies in the public, commercial, or not-for-profit sectors.

\section{Acknowledgements}

Thank a lot for National Institute of Oceanography and Fisheries (NIOF) Marine Data Center for providing the data have been used in this manuscript.

\section{References}

Abbasi, A., Annor, F.O., \& van de Giesen, N. (2017). Effects of atmospheric stability conditions on heat fluxes from water surface in (semi-) arid regions. Hydrological Sciences Journal, 62(9), 1422-1439.

https://www.tandfonline.com/doi/full/10.1080/026266 67.2017.1329587

Béthoux, J., Gentili B., \& Taillez, D. (1999). Warming and freshwater budget change in the Mediterranean since the 1940s, their possible relation to the greenhouse effect. Geophysics Research Letter, 25(7), 1023-1026. https://doi.org/10.1029/98GL00724

Bradley, E.F., Coppin, P.A., \& Godfrey, J.S. (1991). Measurements of sensible and latent heat flux in the western equatorial Pacific Ocean. Journal of Geophysical research: Oceans, 96(S01), 3375-3389. https://doi.org/10.1029/90JC01933

Barsugli, J.J., \& Battisti, D.S. (1998). The basic effects of atmosphere-ocean thermal coupling on midlatitude variability. Journal of the Atmospheric Sciences, 55(4), 477-493. https://doi.org/10.1175/15200469(1998)055<0477:TBEOAO>2.0.CO;2

Chen, H., Schneider, E.K., \& Wu, Z. (2015). Mechanisms of internally generated decadal-to-multidecadal variability of SST in the Atlantic Ocean in a coupled GCM. Climate Dynamics, 46, 1-30. https://doi.org/10.1007/s00382015-2660-8

Cherchi, A., Ambrizzi, T., Behera, S., Freitas, A.C.V., Morioka, Y., \& Zhou, T. (2018). The response of subtropical highs to climate change. Current Climate Change Report, 4:371-382. https://doi.org/10.1007/s40641-018-0114-1

Chou, S.-H., Nelkin, E., Ardizzone, J., R. Atlas, M., \& Shie, C.-L. (2003). Surface turbulent heat and momentum fluxes over global oceans based on the Goddard Satellite retrievals, version 2 (GSSTF-2). Journal of Climate, 16(20), 3256-3273.

https://doi.org/10.1175/15200442(2003)016<3256:STHAMF>2.0.CO;2

El-Geziry, T.M. (2013). On the iurnal variations of in-situ sea surface temperature (SST) in Alexandria Eastern Harbour, Egypt. Journal of Operational Oceanography, 6(2), 1-8. https://doi.org/10.1080/1755876X.2013.11020145

Fairall, C.W., Bradley, E.F., Rogers, D.P., Edson, J.B., \& Young G.S. (1996). Bulk parameterization of air-sea fluxes for Tropical Ocean-Global Atmosphere Coupled-Ocean Atmosphere Response Experiment. Journal of Geophysical Research: Oceans, 101(C2), 3747-3764. http://doi.org/10.1029/95JC03205

Fairall, C.W., Bradley, E.F., Hare, J.E., Grachev, A.A., \& Edson, J.B. (2003). Bulk parameterization of air-sea fluxes: Updates and verification for the COARE algorithm. Journal of Climate, 16(4), 571-591. https://doi.org/10.1175/15200442(2003)016<0571:BPOASF>2.0.CO;2

Feng, L., \& Li, J. (2006). A comparison of latent heat fluxes over global oceans for ERA and NCEP with GSSTF2, 
Geophysical Research Letters, 33(3), L03810. http://doi.org/10.1029/2005GL024677

Frankignoul, C., \& Hasselmann, K. (1977). Stochastic climate models, Part II: Application to sea-surface temperature anomalies and thermocline variability. Tellus, 29A, 289305 http://doi.org/10.1111/j.2153-3490.1977.tb00740.x

Gao, S., Chiu, L.S., \& Shie, C.L. (2013). Trends and variations of ocean surface latent heat flux: Results from GSSTF2c data set. Geophysical Research Letters, 40(2), 380-385. http://doi.org/10.1029/2012GL054620

Han, Z., Luo, F.F., \& Wan, J.H. (2016). The observational influence of the North Atlantic SST tripole on the early spring atmospheric circulation, Geophysical Research Letters, 43(6), 2998-3003. https://doi.org/10.1002/2016GL068099

Herman, A. (2015). Trends and variability of the atmosphereocean turbulent heat flux in the extratropical Southern Hemisphere. Scientific Reports, 5, srep14900 https://doi.org/10.1038/srep14900

Hussein, M.M.A. (2018). Evaluation of Alexandria eastern harbor evaporation estimate methods. Arabian Journal of Geosciences, 11, 768 http://doi.org/10.1007/s12517-018-4139-5

Hussein, M.M.A. (2019). Impact of atmospheric stability conditions on heat fluxes from Alexandria Eastern Harbor, Egypt. Egyptian Journal of Aquatic Research, 45(4), 313-319. https://doi.org/10.1016/j.ejar.2019.10.001

Hussein, M.M.A., \& El-Geziry, T.M. (2014). Diurnal variability of heat fluxes and Bowen Raito over Alexandria Eastern Harbor, Egypt. Journal of King Adul Aziz University: Marine Science, 25(2), 57-85. http://doi.org/10.4197/Mar.25-2.4

Jing, Y., Li, Y., \& Xu, Y. (2020). Assessment of responses of North Atlantic winter SST to the NAO in 13 CMIP5 models on the interannual scale. Ocean Science, 16(6), 15091520. https://doi.org/10.5194/os-16-1509-2020

Kumar, B.P., Cronin, M.F., Joseph, S., Ravichandran, M., \& Sureshkuar, N. (2017). Latent heat flux sensitivity to sea surface temperature: Regional perspectives. Journal of Climate, 30(1), 129-143. https://doi.org/10.1175/JCLI-D16-0285.1

Leyba, I., Solman, S., \& Saraceno, M. (2019). Trends in sea surface temperature and air-sea heat fluxes over the Southern Atlantic Ocean. Climate Dynamics, 53, 41414153. https://doi.org/10.1007/s00382-019-04777-2

Liu, W.T. (1988). Moisture and latent heat flux variabilities in the tropical Pacific derived from satellite data. Journal of Geophysical Research: Oceans, 93(C6), 6749-6760. http://doi.org/10.1029/JC093iC06p06749

Liu, W.T, \& Gautier, C. (1990). Thermal forcing on the tropical Pacific from satellite data. Journal of Geophysical Research: Oceans. 95(C8), 13209-13217. http://doi.org/10.1029/JC095iC08p13209

Liu, W.T., Bishop, J.K.B., Rossow, W., Case, K. (1993). Monthly maps of ocean surface thermal forcing, 1987-1991. JPL Publication. 93-13 Jet propulsion Laboratory, Pasadena, CA, 17.

Lolis, C.J., Bartzokas, A., \& Katsoulis, B.D. (2004). Relation between sensible and latent heat fluxes in the Mediterranean and precipitation in the Greek area during winter. International Journal of Climatology, 24(14), 1803-1816. http://doi.org/_10.1002/joc.1112

Millot, C., Candela, J., Fuda, J.L., \& Tber, Y. (2006). Large warming and salinification of the Mediterranean outflow due to changes in its composition. Deep-Sea Research I: Oceanographic Research Papers, 53(4), 656-666. https://doi.org/10.1016/j.dsr.2005.12.017

Methew, S., Latha, G., \& Venkatesan, R. (2020). Latent heat flux variation during the warming phase of intraseasonal oscillations over northern Bay of Bengal. Journal of Earth system Science, 129, Article ID 0070. https://doi.org/10.1007/s12040-019-1338-8

Murakami, H., \& Kawamura, H. (2001). Relations between Sea Surface Temperature and Air-Sea Heat Flux at Periods from 1 Day to 1 Year Observed at Ocean Buoy Stations around Japan. Journal of Oceanography, 57, 565-580. http://doi.org/10.1023/A:1021530903138

Neelin, J.D., \& Held, I.M., (1987). Modeling tropical convergence based on the moist static energy budget. Monthly Weather Review, 115(1), 3-12.

https://doi.org/10.1175/1520 0493(1987)115<0003:MTCBOT>2.0.CO;2

Nisha, P.G., Muraleedharan, P.M., Keerthi, M.G., Sathe, P.V., \& Ravichandran, M. (2012). Does sea level pressure modulate the dynamic and thermodynamic forcing in the tropical Indian Ocean? International Journal of Remote Sensing, 33(7), 1991-2002. http://doi.org/10.1080/01431161.2011.604653

Potter, R., \& Lozier, S. (2004). On the warming and salinification of the Mediterranean outflow waters in the North Atlantic. Geophysics Research Letter, 31(1), CiteID L01202. http://doi.org/10.1029/2003GL018161

Ramanathan, V., \& Collins, W. (1992). Thermostat and global warming. Nature, 357, 649 . http://doi.org/10.1038/357649a0

Ruiz, S., Gomis, D., Sotillo, M.G, \& Josey, S.A., (2008). Characterization of surface heat fluxes in the Mediterranean Sea from a 44-year high-resolution atmospheric data set. Global and Planetary Change, 63(2-3), 258-274. https://doi.org/10.1016/j.gloplacha.2007.12.002

Renfrew, I.A., Moore, G.W.K., Guest, P.S., \& Bumke, K. (2002). A comparison of surface layer and surface turbulent flux observations over the Labrador Sea with ECMWF analyses and NCEP reanalysis. Journal of Physical Oceanography, 32, 383-400. https://doi.org/10.1175/15200485(2002)032<0383:ACOSLA>2.0.CO;2

Sanchez-Gomez, E., Somot, S., Josey, S.A., Dubois, C., Elguindi, N., \& De'que, M. (2011). Evaluation of Mediterranean Sea water and heat budgets simulated by an ensemble of high resolution regional climate models. Climate Dynamic, 37(9), 2067-2086. http://doi.org/10.1007/s00382-011-1012-6

Seager. R., Murtugudde, R., Clement, A., \& Herweijer, C. (2003). Why is there an evaporation minimum at the equator? Journal of Climate, 16(122), 3793-3802. https://doi.org/10.1175/15200442(2003)016<3793:WITAEM>2.0.CO;2

Sobel, A.H. (2003). On the coexistence of an evaporation minimum and precipitation maximum in the warm pool. Journal of Climate, 16(6), 1003-1009. https://doi.org/10.1175/15200442(2003)016<1003:OTCOAE >2.0.CO;2

Sui, C.H., Lau, K.M., \& Betts, A.K. (1991). An equilibrium model for he coupled ocean-atmosphere boundary layer in the Tropics. Journal of Geophysics Research, 96, 3151-3163.

Taylor, C.M., Ellis, R.J., Parker, D.J., Burton, R.R., \& Thorncroft, 
C.D. (2003). Linking boundary-layer variability with convection: A case-study from JET2000. Quarterly Journal of the Royal Meteorological Society, 129(592), 2233-2253.

https://doi.org/10.1256/qj.02.134

Vizy, E.K., Cook, K.H., \& Sun, X. (2018). Decadal change of the South Atlantic Ocean Angola-Benguela frontal zone since 1980. Climate Dynamics. 51:3521-3273. https://doi.org/10.1007/s00382-018-4077-7

Wallace, J.M. (1992). Effect of deep convection on the regulation of tropical sea surface temperature. Nature, 357, 230-231. https://doi.org/10.1038/357230a0

Weare, B.C., Strub, P.T., \& Samuel, M.D. (1981). Annual mean heat fluxes in the tropical Pacific Ocean. Journal of Physical Oceanography, 11, 705-717.

Wu, R., Kirtman, B.P., \& Pegion, K. (2006). Local air-sea relationship in observations and model simulations. Journal of Climate, 19(19), 4914-4932. https://doi.org/10.1175/JCLI3904.1

Wu, R., Kirtman, B.P., \& Pegion, K. (2007). Surface latent heat flux and its relationship with sea surface temperature in the National Centers for Environmental Prediction Climate Forecast System simulations and retrospective forecasts. Geophysical Research Letters, 34(17), L17712. https://doi.org/10.1029/2007GL030751

Wu, R., \& You, T. (2018). Summer intraseasonal surface heat flux-sea surface temperature relationship over northern tropical Indo-western Pacific in climate models. Journal of Geophysical Research: Atmospheres, 123, 5859-5880. https://doi.org/10.1029/2018JD028468

Yu, L., Zhang, Z., Zhou, M. Zhong, S., Lenschow, D.H., Li, B., Wang, X., Li, S., Wu, H., \& Sun, B. (2012). Trends in Latent and Sensible heat flux over the Southern Ocean. Atmospheric and Climate Sciences, 2, 159-173. http://dx.doi.org/10.4236/acs.2012.22017

Zhang G.J., \& McPhaden, M.J., (1995). The relationship between sea surface temperature and latent heat flux in the equatorial pacific. Journal of Climate, 8(3), 589-605. https://doi.org/10.1175/15200442(1995)008<0589:TRBSST>2.0.CO;2

Zeng, X., Zhao, M., \& Dickinson, R.E. (1998). Inter-comparison of bulk aerodynamic algorithms for the computation of sea surface fluxes using TOGA COARE and TAO data. Journal of Climate, 11(10), 2628-2644. https://doi.org/10.1175/15200442(1998)011<2628:IOBAAF>2.0.CO;2 